\title{
Climate Change Adaptation in the Pacific Island Tourism Sector: Analysing the Policy Environment in Vanuatu ${ }^{1}$
}

\author{
Louise Munk Klint, Emma Wong, Min Jiang, Terry DeLacy ${ }^{\mathrm{a}}$, \\ David Harrison ${ }^{\mathrm{b}}$, \\ Dale Dominey-Howes ${ }^{c}$
}

${ }^{a}$ Centre for Tourism and Services Research, Victoria University, Footscray, Australia

${ }^{\mathrm{b}}$ School of Tourism and Hospitality, University of South Pacific, Suva, Fiji

${ }^{c}$ Natural Hazards Research Laboratory, University of New South Wales, Sydney, Australia

Corresponding author - louise.klint@live.vu.edu.au

Tourism is a growing economic sector in the South Pacific providing the region with great potential for economic development. Vanuatu and its neighbouring Small Island Developing States (SIDS) experience a high vulnerability to climate change impacts. The Island's tourism sector is particularly vulnerable and it needs to develop and implement effective adaptation strategies to reduce climate change risks. Policies play an important role by providing the platform on which adaptation can occur and resilience be built. This study examines the policy environment in Vanuatu for its conduciveness to climate change adaptation. It identifies the types of adaptation processes (explicit or implicit) and types of adaptation measures (technical, business management, behavioural, policy, and research \& education) and critically analyses the current tourism related policies for their effectiveness in assisting the sector addressing climate change. It was found that the majority of policies identified deal with climate change through implicit adaptation processes and mainly through the use of policy and research and education measures. The authors argue that in order to strengthen the resilience of the tourism industry, the Government of Vanuatu needs to develop and implement explicit climate change adaptation policies for the tourism sector.

Keywords: tourism, climate change, adaptation, adaptive capacity, policies, Vanuatu

\footnotetext{
${ }^{1}$ This research is funded by an AusAID Australian Development Research Award
} 


\section{Introduction}

Tourism is a growing market in the Pacific region providing great potential for economic development. The contribution of tourism to Gross Domestic Product (GDP) in Pacific Island Countries (PICs) is typically in the order of 20 percent and is a key employer in the region providing approximately 15 percent of jobs in PICs (UNESCAP, 2009).

SIDS are the most vulnerable of all nations to the impacts of climate change (IPCC, 2007a). Sem and Moore (2009) identify eight characteristics that make SIDS particularly vulnerable to climate change ranging from limited natural resources to limited funds and human resource skills. A recent Oxfam Report states, 'climate change has the potential to affect almost every issue linked to poverty and development in the Pacific' (Maclellan et al., 2009, p. 7).

The natural environment in the form of marine and terrestrial attractions is a crucial resource for the development of the tourism sector in PICs (Harrison 2003). The SIDS in the Pacific region have been identified as a hotspot for vulnerability (Scott et al., 2008a) and the ecosystems on which most PIC tourism activity is based will be impacted by climate change (Becken and Hay, 2007). For example even modest ocean warming causes coral bleaching (Riegl et al., 2009). Sea level rise and resultant inundation from storm surge threatens coastal assets (Sem and Moore, 2009). Storms pose a real threat to tourism infrastructure (Gössling and Hall, 2005) and have been predicted to increase in intensity (Preston et al, 2006). On top of the above mentioned impacts on tourism supply, tourism demand will also be affected by climate change. International action to mitigate Green House Gas (GHG) emissions will increase travel costs, especially for long haul travel and ethical concerns regarding air transport will affect consumer demand for different destinations, potentially impacting on PIC tourism (DeLacy and Lipman 2010). Consequently, the PICs tourism sector needs to urgently address climate change to minimise its potential risk.

Mitigation and adaptation are the two key approaches to manage risks from climate change. In order to slow or prevent climate change, mitigation aims to reduce greenhouse gas (GHG) emissions, whereas adaptation measures lessen the vulnerability to the effect of climate change (Sanderson \& Islam, 2007). Adaptation is 
the principal way to deal with the unavoidable consequences of climate change in the short term. It can be seen as a mechanism of managing risks, reducing vulnerability by adjusting economic activity and improving business certainty (COAG, 2007).

Therefore, PICs will need to develop appropriate frameworks for use by the local tourism industry to adapt to climate change. National policies will need to take account of this urgent need to develop such frameworks and be conducive to their implementation in the medium to long term.

With a view of recommending an appropriate policy setting for PICs to assist their tourism sector adapt to climate change, a research team established under an Australian Development Research Award have reviewed and analysed the existing relevant policy environment in PICs.

The objectives of the policy analysis were: 1) to create an inventory of policies pertinent to PIC tourism climate adaptation; 2) to examine the policy-making environment; 3) to examine the policy-making mechanisms and implementation; 4) to identify policy gaps; and to provide input into the evaluation of adaptive capacity of the tourism sector.

In this paper, we examine the policy environment in Vanuatu, a PIC where tourism is the dominant sector (ADB, 2009; Méheux and Parker, 2004), for its conduciveness to climate change adaptation.

The paper briefly reviews climate change adaptation literature related to the tourism sector, outlines the projected climate change impacts for the Pacific region with particular reference to Vanuatu, and discusses how these might influence the tourism sector. The next section describes the methodology and methods used to review and analyse the relevant policy environment in Vanuatu. The paper then presents the policy analysis and discusses how conducive the policies are for Vanuatu's tourism sector to adapt to climate change. Finally, the paper makes recommendations on possible policy reform.

\section{Background}

Even though there is still much uncertainty in relation to the parameters of climate change, we now have enough knowledge at hand to accept that climate change is occurring and this has been primarily caused by anthropogenic activities. There is even more uncertainty as to the detail of the resultant physical, biological, economic, political and social impacts but the risk of very severe consequences are high 
(Garnaut, 2008; Stern, 2006). It is widely accepted that adaptation measures need to be taken now to address these climate change risks (Dazé et al., 2009; UN-OHRLLS, 2009; Green, 2008; Pearman, 2008; IPPC, 2007b; Preston et al., 2006).

\section{Adaptation to climate change in the tourism sector}

Climate change adaptation has been defined by the IPCC (2007) as "the adjustment in natural or human systems in response to actual or expected climatic stimuli or their effects, which moderates harm or exploits beneficial opportunities' (p. 6). Adaptation can occur on a spectrum ranging from simple measures, such as the replanting of mangroves, to more involved and costly measures, such as the construction of a seawall.

Aiming to minimise negative impacts and to identify and take advantage of opportunities or potential positive changes resulting from climate change, adaptation involves different tourism stakeholders at all level from the individual to the organization, both public and private sectors, as well as households and communities (Simpson et al., 2008).

Scott et al. (2008b) highlighted five types of adaptation measures that are relevant to the tourism sector: 1) technical adaptation- i.e. changes made to physical infrastructure or provisions; 2) business management adaptation - i.e. changes made by the private sector in their businesses; 3) behavioural - i.e. behavioural changes made by tourists or communities; 4) policy - i.e. changes in government plans or strategies; and 5) research \& education - i.e. initiatives to strengthen the understanding of adaptation, explore adaptation options, and educating communities. Besides the types of adaptation, there is also a difference in the processes by which it is implemented.

Hall et al. (2005) identified that adaptation to climate change involves different processes "in the case of actual negative changes in the resource base for tourism that could be caused by climate change" (p. 212): explicit and implicit. Explicit climate change adaptation processes occur within a climate policy context, whereas implicit climate change adaptation processes do not link to climate policies.

Consequently, climate change adaptation in tourism can be implemented through the use of five adaptation types; 1) technical, 2) business management, 3) behavioural, 4) policy, and 5) research \& education (Scott et al., 2008) via explicit and/or implicit adaptation processes (Hall et al., 2005), as shown in Figure 1. 
[Insert Figure 1 here]

\section{Impact of Climate change on PICs and Vanuatu's tourism sector}

Tourism represents a significant economic sector. Vanuatu - an archipelago of 83

islands - offers great tourism attractiveness in the form of different cultures, volcanoes, pristine beaches and underwater environments (Vanuatu Tourism Office, 2009). From 1995 to 2008, the tourism sector has seen an annual average growth of 6.45 per cent with the total visitor arrivals reaching 196795 in 2008 (Vanuatu National Statistics Office, 2009). Tourism represents the key foreign exchange earner in Vanuatu (Méheux and Parker, 2004). In 2007, it represented 15.3 per cent of the country's GDP and employed directly 14.1 per cent of the country's population (WTTC, 2009).

The climate is a key factor taken into account in the decision process of destination choice (Uyarra et al., 2005) which is particularly the case in Vanuatu. In the 2004 Vanuatu Visitor Survey Report ${ }^{2}$, climate ranks as the second highest decision making factor with friendly people being the most important and the most common type of activity engaged in by visitors while in Vanuatu is snorkeling (Vanuatu National Statistics Office, 2007). Thus, any changes to the climate may impact on the visitor numbers in Vanuatu.

Climate change is affecting the tourism sector now and will continue to impact tourism around the world at an increasing rate (Scott et al., 2008; Gössling et al., 2005). Climate change will affect the natural attractions of Vanuatu through coral bleaching, sea level rise and coastal inundation. The main climate change issues and vulnerabilities identified by the Republic of Vanuatu (2007) as affecting the various provinces of Vanuatu are: 1) Coastal erosion; 2) Cyclones; 3) Flooding; 4) Salt water intrusion; 5) Scarcity of water resources; 6) El Niño events resulting in drought; 7) Landslides associated with prolonged and intense rainfall; 8) Declining crop production; 9) Changes in temperatures; and 10) Distribution of mosquitoes. In addition to the impact of a possible decrease in attractiveness, Vanuatu may also be

\footnotetext{
${ }^{2}$ The National Statistics Office undertook a visitor survey in 2004 with 5000 surveys completed. Out of these 4982 forms were usable for analysis and the report divided into three areas: visitor profile, travel behaviour and visitor expenditure (Vanuatu National Statistics Office, 2007).
} 
facing changes to international travel flows. Thus, adaptation will be vital for this nation and its tourism sector to cope with the impacts of a changing climate.

Moreover, Vanuatu is highly vulnerable to climate change due to its status as a SIDS and its status as a Least Developed Country (LDC) (Sem and Moore, 2009). The IPCC (2007b) stated with very high confidence ${ }^{3}$ that small islands are "especially vulnerable to the effects of climate change, seal-level rise, and extreme events" (p. 689) due to a number of country characteristics. Eight SIDS characteristics have been identified: 1) limited size; 2) limited natural resources; 3) natural hazards; 4) water; 5) low economic resilience; 6) population growth and density; 7) infrastructure; and 8) limited funds and human resource skills (Sem and Moore, 2009).

SIDS also have a number of strengths and adaptation policies must identify these strengths and develop strategies that build on these strengths. Scheyvens and Momsens (2008) highlighted six strengths of small island states: 1) small is beautiful; 2) small islands are good economic performers; 3) high levels of cultural, social and natural capital; 4) respect for traditional, holistic approaches to development; and 5) strong international linkages and political strength. Consequently, climate change adaptation policies in Vanuatu should take account for the vulnerabilities of the nation and identify and build on its strengths.

\section{Methods: Reviewing and analysing the relevant policy environment in Vanuatu}

The five basic elements of Leiper's (2004) tourism system model include: 1) tourists, 2) tourist generating regions (TGR), 3) tourist destination regions (TDR), 4) transit route (TR), and 5) tourism industries. These elements do not exist in a vacuum; they are embedded within a wider socio-political, economic and environmental context that shapes every aspect of the system from the tourist's desires and expectations through to legal parameters of travel (visa requirements, airline emissions standards and flight curfews), tourism planning and policy structures and processes, and economic revenue flows that run through the economic goods and services value chain. Tourism activity does centre on the destination but the impact and consequences of shocks and more slow-onset stressors like global warming and sealevel rise on one part of the system reverberates throughout the entire system.

\footnotetext{
${ }^{3}$ IPCCs description of likelihood - very high confidence means at least nine out of ten chance of being correct.
} 
Accordingly, it is imperative to identify the main components that make up the destinations tourism system and to understand the interlinkages and relationships that exist between these elements as well as the contextual environments within which the system operates. A key component of the contextual environment is the policy environment of government within which the tourism system sits (Gunn, 1994). As acknowledged by Scott et al. (2008a), only a few countries in the world have developed specific tourism climate change adaptation policies. However, numerous Governments have developed generic climate change policies many of which affect the tourism sector. Consequently, to understand the policy context for the tourism sector's adaptation to climate change our research focussed on policies in the following four areas: (1) climate change, (2) environment, (3) tourism, and (4) disaster management (Jiang et al., 2009).

We applied the conceptual adaptation framework shown in Figure 1 to our policy analysis with the five adaptation types identified within the objectives, strategies and actions of the policies. The explicit policies are those that are, wholly or partly, formulated with the intention to address climate change and implicit policies are those that are formulated with the intention to address issues other than climate change, but have components that are pertinent to climate change.

Data was collected during a fieldtrip to Vanuatu in November and December 2009. Information was collected from both secondary and primary sources. Secondary resources provided the background information about the geography, history, politics and institutional structure, economy, and climate change related hazards of Vanuatu as well as establishing an outline of Vanuatu's tourism system. An inventory of policies that were pertinent to climate change adaptation of the tourism sector was created by referring to official policy documents or to other media (e.g. news reports, research papers etc.).

Primary data was collected to examine policy issues from multiple perspectives, and to provide insights into the policy process that may be too sensitive to be documented. It was obtained by means of semi-structured in-depth interviews with key informants, selected through purposeful sampling methods. The use of purposeful sampling techniques allowed for selecting information-rich cases that could provide much information about the issues being studied (Patton, 2002). Nevertheless, snowball sampling techniques were also utilised, where well-situated people were asked to identify information-rich key informants (Patton, 2002). 
In total, 27 interviews were held with representatives of five stakeholder groups: 1) national and local government bodies; 2) tourism industry; 3) donor and development organisations; 4) non-governmental organisations; and 5) research institutes or universities. The interviews were, on average, 40 minutes in length. The interview structure contained the following elements: 1) Introduction; 2) Scoping; 3) Policy Purpose; 4) Conceptualisation; 5) Decision; 6) Implementation and Coordination; 7) Outcome; and 8) Implications for Climate Change Adaptation for the Tourism Sector. Interviewing stopped when the data saturation point was reached (Minichiello et al., 1995), i.e. when the themes emerged from the interviews started to repeat themselves. The interviews were analysed using NVivo software.

The policies were analysed using the framework developed in Figure 1 and their ability to address SIDS characteristics.

\section{Results: Vanuatu's policy environment; How conducive is it to developing an adaptation framework for the tourism sector?}

\section{Vanuatu's tourism system}

The involvement of all stakeholders of the tourism system in the development of a destination adaptation strategy is essential to ensure its successful implementation (Jopp, 2010; Simpson et al., 2008). Consequently, an understanding of the tourism system in Vanuatu is crucial in order to .review the related policy environment

[Insert Figure 2 here]

Leiper's (2004) model is used to briefly describe the tourism system in Vanuatu under the three geographical elements (see Figure 2). Not surprisingly Vanuatu's tourism system is dependent on regional markets linked by air and cruise ship transport, is built around its natural and cultural resource assets, its infrastructure mainly coastal and its related government agencies and industry bodies are very much in their early stages of development.

Within this context of Vanuatu's tourism system, Vanuatu's policy environment is analysed to: 1) create an inventory of policies pertinent to PIC tourism climate adaptation; 2) examine the policy-making environment; 3) examine the 
policy-making mechanisms and implementation; and 4) identify policy gaps; and to provide input into the evaluation of adaptive capacity of the tourism sector.

\section{Inventory of policies that are pertinent to climate change adaptation}

Twenty-seven policies (27) were identified as potentially pertinent to climate change adaptation. Out of the 27 policies identified only four (4) explicit policies were identified (see light grey highlight in Table 1), the remaining 23 policies were implicit policies (see Table 1). From the analysis, it was found that there were no tourism policies that explicitly dealt with climate change adaptation. However, a number of generic climate change policies did address the tourism sector's adaptation to climate change. Furthermore, a number of other sector policies and tourism plans may assist the tourism sector in addressing climate change.

[Insert Table 1 here]

Vanuatu ratified the UNFCCC in 1993 and the Kyoto Protocol in 2001 (see Figure 2). Both of these ratifications have helped the nation in putting climate change on the country's agenda. The National Advisory Committee on Climate Change (NACCC) was re-formed in 1997, as a result of the implementation of the Pacific Islands Climate Change Assistance Programme (PICCAP). It was first established in 1989 (Silas-Nimoho and Whyte, 1999). In 1999, the Initial National Communications were submitted to the UNFCCC and following this a number of explicit climate change policies have developed in the region and within Vanuatu. It is noteworthy to mention that the proposed national Climate Change Policy framework highlights some of the critical sectors that are directly impacted by climate change, but neglects to mention the tourism sector.

[Insert Figure 3 here]

The four (4) explicit climate change policies identified in Vanuatu are: 1) A Climate Change Policy and Implementation Strategy Discussion Paper for Vanuatu (hereafter named Climate Change Policy) 2) National Adaptation Programme for Action (NAPA) 2007; 3) Pacific Adaptation to Climate Change (PACC) 2009; and 4) Pacific Islands Framework for Action on Climate Change 2006 - 2015. The latter 
policy is a regional policy, whereas the Climate Change Policy, the NAPA and the PACC are national policies of Vanuatu. The Pacific Islands Framework for Action on Climate Change 2006-2015 provides a guiding model for Vanuatu in acting on climate change, whereas the national policies will help the country walk the talk. As mentioned by an interviewee from the Government pool, the national climate change policy is being drafted and should be completed in 2010. Besides the explicit policies, 23 implicit policies have components that will help the tourism sector in Vanuatu address climate change.

In recent years, the Vanuatu Government has acknowledged the importance of the tourism sector to secure economic growth and have developed a number of policies related to tourism. According to an interviewee from the Government, "the national tourism office was first established in the 1980s when it was decided by the national planning office that a sector plan should be written to guide further development of tourism and to further grow this sector". This policy was brought into life in 1995 when the World Tourism Organisation prepared a tourism development master plan for Vanuatu, which was endorsed by the Government (VNSO, 2007). This has since been updated and the Vanuatu Tourism Development Master Plan 2004-2010 sets out the overall policy for the tourism sector, and will be implemented through the Vanuatu Tourism Action Program (VTAP) 2008 and its sub-sector plans (e.g. regional tourism development plans and destination marketing plan).

None of these policies acknowledge climate change or include explicit climate change adaptation measures, yet elements of these plans will help the tourism sector adapt to climate change, as highlighted in Table 1 and 2. For example, the Vanuatu Tourism Action Program (VTAP) 2008, which is currently in the process of being implemented, involves a range of technical, business management, policy, and research \& education adaptation types of measures. One example is the support of the geographic spread of tourism by incorporating provincial tourism products and icons into the VTO marketing, hence diversifying the product offering and enhancing the overall resilience of the tourism sector. In a similar vein the implementation of an international aviation strategy is another example of policies "implicitly" contributing to climate change adaptation in the tourism sector.

Environment and disaster risk management policies also impact on the tourism sector. Seven implicit policies are identified within the environment and disaster risk management policy area that are conducive to assisting adaptation to climate change 
in the tourism sector. The Disaster Risk Reduction and Disaster Management National Action Plan 2006-2016 entails technical, business management and policy types of adaptation by for example facilitating the implementation of early warning systems which can reduce the vulnerability of the tourism sector to climate change induced risks like cyclones and storm surges.

There are six implicit policies identified under the environment. One policy is regional, two are national, and the remaining three are provincial/local. As an example the Environmental Management and Conservation Act 2002 provided technical, policy, and research \& education adaptation types whereby for example establishment of conservation areas protect Vanuatu's natural resources, which provide future tourism attractions. Thus, making tourism less vulnerable to climate change induced ecosystem damage.

Twelve implicit policies do not fit into the three key policy areas identified, but are also pertinent to the Vanuatu tourism sector's adaptation to climate change. For example, the technical adaptation of improving transportation infrastructure and services under the Millennium Challenge Account Vanuatu 2006-2010 policy will enhance access to a broader range of tourism attractions with resultant flexibility and lessened vulnerability of the tourism sector. With the exception of the National Action and Priorities Agenda these 'other' implicit policies can be divided into three policy areas: fisheries, infrastructure, and economic and social development.

The combination of explicit and implicit policies should facilitate a broad range of possible adaptation measures within all five adaptation types.

\section{The policy-making environment}

Vanuatu is governed by the Constitution of Vanuatu, which was established in 1980.

The Constitution sets out that "The Republic of Vanuatu is a sovereign democratic state" (The People of Vanuatu, 1980, p. 4). As stated by the Parliament of Vanuatu (2009), the nation's government structure is based on the Westminster model of Government. Key features of the Westminster model become apparent in the political structure of the Government of Vanuatu. The main figure head of Vanuatu is the President, who is elected for a 5- year term and has mainly ceremonial powers, whereas the Prime Minister is the head of Government and together with the elected Ministers represent the executive Government of Vanuatu (Parliament of Vanuatu, 2009). 
The Government of Vanuatu is divided into twelve Government Ministries and six Provincial Governments. The three Ministries of key importance to the tourism sector's adaptation to climate change are: (1) the Ministry of Public Works (parent ministry of the Ports \& Harbour Department, Meteorological Services Unit, and Airports Vanuatu Ltd.), (2) the Ministry of Lands and Natural Resources (parent ministry of the Environment Department), and (3) the Ministry of Trades, Commerce, Industry and Tourism (parent ministry of the National Tourism Development Office (NTDO), the Vanuatu Tourism Office (VTO), and the Vanuatu Investment Promotion Authority (VIPA)), as highlighted in Figure 4.

[Insert Figure 4 here].

The Ministry of Trades, Commerce, Industry and Tourism is the most important Ministry for the tourism sector, as it includes the NTDO, the VTO and the VIPA. A tourism statutory body was established in Vanuatu under the Vanuatu Tourism Office Act in 1982. The main strategic directives of a tourism statutory authority are aimed at commercial activities and marketing (Dredge and Jenkins, 2007). The VTO is mainly oriented towards marketing of Vanuatu in domestic and overseas markets and thereby aims to promote and encourage the sustainable development of tourism in Vanuatu. The NTDO is the ministerial department for tourism planning and policy making and works closely with the VTO. The VIPA is the body controlling and promoting foreign investment in Vanuatu, and consequently also plays a significant role in the tourism sector, which involves a large percentage of foreign investors. One interviewee from the industry group mentioned that 50 per cent of the Vanuatu Tour Operators Association's members are foreigners, highlighting the importance of the involvement of VIPA.

From the interviews, there seemed to be a general lack of awareness within the tourism industry of the policies relevant to the sector. Furthermore, Government officials raised concerns in regards to the drafting and implementation of policies. As an example, an interviewee from the Government pool of interviews indicated the climate change policy had been in drafting stage since 2002 and had not been completed due to a disagreement whether the policy document and the implementation strategy should be in one document or in two. Another interviewee 
from the Government mentioned that there was a real issue in relation to the implementation of plans, as the Government official stated "will there be enough funding to implement the plan within this timeframe?".

\section{Policy-making mechanisms}

From an analysis of the primary data collected, it becomes obvious that although the Government of Vanuatu and its departments attempt to be transparent in the way policies are developed and implemented there is a limited knowledge of the Government policies within the tourism industry. One interviewee claimed they are "not aware of any policies, as they are completely inactive"; another interviewee from the industry said: "policies are in place, but not implemented"; and a third industry players said: "nothing ever happens - it just gets shelved" when discussing policy guidelines developed by international donor organisations. Thus, although there seem to be some awareness of the presence of documents, either the implementation of these are not transparent or that the policies are not implemented.

Developing effective climate change policies requires enormous coordination across government and considerable sophistication in implementation. Within Government, one interviewee highlighted the need for all Government departments to work together, as "everything will be impacted by climate change". Nevertheless, this same interviewee provided examples of current projects involving Government where cross-sectoral dialogue has not involved all governmental stakeholders. The completion and implementation of the national climate change policy may help encourage the cross-sectoral dialogue, as "the main purpose of the policy is to mainstream climate change in the decision-making process of all sectors". An interviewee from the industry group believes that the "current focus is on disaster risk management, in relation to Tsunamis and earthquakes and cyclones and that most [industry players] feel that the impacts of climate change are out of their hands and should be the focus of Government".

The policy-making mechanisms in Vanuatu do involve participatory processes. One interviewee from the industry highlighted workshops as part of the policy-making process, but then highlighted issues related to the consultation of the industry and the general public prior to the policy development. The interviewee mentioned that short notice is being given (approx. three days) and "speeches and food seem to be the main focus" and as "the private sector is not paid to be there they 
feel they are wasting their time". This came from an interviewee, who seemed to be heavily involved in the tourism sector encouraging it to be more sustainable and willing to put in the hard work to achieve this goal. The interviewee further stated that "meeting minutes are not followed through". This is supported by another interviewee from the industry groups, who mentioned that "there is a lack of transparency".

This highlights a concern that the consultation process seems to be based on process rather than performance. Nevertheless, it could be that apathy and a lack of involvement by industry players contributes to difficulties in implementation. One example was mentioned by a fourth industry player, who said that "only two expatriate operators [were] at the launch of the [SANMA] tourism plan".

Consequently, future directions by Government should include strategies in how to empower the tourism sector and build community spirit and support for Government policies.

As an interviewee from the industry mentioned, "they [the Government] often hire consultants in Australia, but the policy says to hire local consultants. This is not enforced either". The question is whether the local People are involved enough in these types of projects to develop a sense of ownership and support for these policies. Perhaps this is why it seems, as suggested by several industry players, that most of the international donor agency developed policies end up on the shelf and are never implemented. As one interviewee highlighted, "it is disheartening to see all the good work end up as white paper".

\section{Policy Gaps}

The conduciveness of a policy environment can be assessed based on 1) the level of commitment of key stakeholders to the policy agenda; 2) resources availability; and 3) presence of an enabling policy mechanism (Wong et al., 2010).

In terms of Vanuatu, the commitment by key stakeholders to the policy agenda is in the developing stage; climate change has entered the policy arena, but is not yet a key focus. With the completion of the national climate change policy, this gap will be bridged by mainstreaming climate change in all sector policies. A vital example of this gap is the lack of explicit policies in the tourism sector.

The resources available for climate change adaptation in tourism are somewhat limited. This can be seen in the example of the reduction of the VTO budget, which has recently been cut by a third from 150 million Vatu to 100 million 
Vatu (Nadkarni, 2007), thereby reducing the sector's ability to plan long-term and be flexible. Nevertheless, Vanuatu is receiving funds from the LDC fund and a number of aid agencies, e.g. AusAid, ADB and Millennium Challenge Account, spend considerable funds on climate change related projects in Vanuatu, as well as in other PICs. Thus, once climate change has been incorporated in all sector policies, this gap may be bridged.

The presence of an enabling policy mechanism can be seen in terms of the number of explicit and implicit policies identified in this analysis, the presence of consultation processes, and the growing inclusion of climate change in the policy arena. However, in many cases foreign consultants are hired to develop the plans and strategies, which may prevent a sense of ownership of these policy documents thereby weakening the successful implementation rate. Consultation processes with local communities and industry players seem to be more process than performance oriented, which again weakens the effectiveness of the enabling policy mechanisms. Not all policies are implemented or enforced due to a lack of financial as well as human resources and skills. The national climate policy together with any tourism sector's explicit climate change policy if and once developed and implemented may partly address this gap.

As identified in the literature, SIDS characteristics can contribute to these nations' vulnerability to climate change (Sem and Moore, 2009; Scheyvens and Momsens, 2008; IPCC, 2007b). For example, the limited population, economic and geographical size of most SIDS provides many constrains. For tourism it means that there are limited opportunities for expansion of infrastructure and the development of new natural attractions. Thus, this characteristic means that the Government of Vanuatu will be facing an additional challenge in making its small size an advantage in dealing with climate change instead of a vulnerable feature of this nation.

How then does this mix of policies (see Table 2) address the SIDS characteristics that make Vanuatu more vulnerable to climate change?

[Insert Table 2 here]

Overall, the SIDS characteristics that contribute to Vanuatu's vulnerability are being addressed through the mix of explicit and implicit policies with the two most addressed SIDS characteristics being limited funds and human resource skills (24 out 
of 27 policies) and limited natural resources skills (23 out of 27 policies). The least addressed SIDS characteristics are the limited size (2 out of 27 policies) followed by water (6 out of 27 policies) and population growth and density (6 out of 27 policies). Although, it is not always possible for policies to address all of the SIDS characteristics, it is important to acknowledge these characteristics as contributing to vulnerability, address them where appropriate, and build on the strengths and opportunities of the nation.

\section{Discussion/Conclusion (500 words - currently 797 words)}

Firstly, the main conclusions from the policy analysis are: 1) a number of explicit and implicit policies do address climate change issues that will enable Vanuatu generally and its tourism sector more specifically to adapt to climate change; 2 ) only one policy is explicitly concerned with both tourism and climate change; and 3) none of the tourism plans identify climate change as a risk and do not set out actions to adapt to future climate change risks. The Vanuatu tourism master plan and the current two provincial tourism plans do not consider climate change at all.

Secondly, the implementation of policies seems to be a real issue in Vanuatu. Adaptation policies, like all policies, are only effective if implemented and reviewed on a regular basis. Our study highlighted that climate change does not rate highly on the political agenda for government administration and financial resources to implement policies more broadly are strained.

For example, an interviewee from the Industry group showed the interviewer a piece of paper and said the following while he pointed at the piece of paper, "a person once told me that if you take a piece of paper and say this is the environment, then climate change is just a tiny little corner of the paper". Another interviewee from the Industry said that there is "no back-up or funding from the Government to deal with climate change and that it is the rest of the world that will have to pull up the Pacific countries". Although this is a very cynical view of the situation there is some truth in the matter as Vanuatu, a LDC, cannot afford to allocate sufficient resources (Sem and Moore, 2009; Republic of Vanuatu et al., 2007) to undertake the many adaptation actions that may be required to make its tourism sector more resilient to climate change risks.

There will be some costly technical adaptations needed to address the impacts of climate change on the natural resources and ecosystems crucial to the tourism's 
sector. Nevertheless, not all policies have to be costly to implement; basic community run or driven projects and policies can be very effective. Two excellent examples in Vanuatu were provided by interviewees from the NGO group. One interviewee explained about their NGOs community outreach programs and how a theatre group would perform when a new committee was set up and consequently provide awareness through their performance. The other interviewee explained how the understanding of the life cycle of a specific species leads to a better caring of this species.

The Government of Vanuatu has also implemented a climate change adaptation initiative, which has proven to be successful. An interviewee from the Government explained how "a Giant Clams farming project was developed to stop locals from exporting wild clams". As mentioned by the interviewee, this project not only helps address the issue of a declining population of clams (limited natural resources), but that the project also "will provide another option and revenue system for these communities" including viewing for divers (tourists).

This was further backed up by an interviewee from the Government, who identified "a lack of awareness in relation to policies in the following areas: (1) what is out there, (2) what are the impacts of climate change on tourism, (3) what needs to be done, (4) what are tourism "tides" and (5) what are the skills within tourism.

In summary, although climate change is considered important in some sections of government there is little awareness of its importance in the tourism sector especially "on the ground". This is a significant problem as what makes climate change such an important issue to deal with at Government level is that it exacerbates current stressors (Gössling, 2006, Preston et al., 2006) as well as creating new stressors.

As identified in a Pacific 2020 project (Commonwealth of Australia, 2006), implementation serve as a serious constrain in Pacific countries and it "is a function of ownership" (p. 4). Consequently, Vanuatu needs to focus on building a sense of ownership to projects and policies undertaken within the country through putting in place realistic reform plans and prioritising these and encouraging governance in a Pacific context (Commonwealth of Australia, 2006).

Further research should be undertaken in identifying the risks of climate change for the tourism sector in Vanuatu. Most importantly, the tourism sector needs to ensure that the tourism sector is explicitly considered in all climate change 
adaptation policies and strategies and that all tourism plans have the inclusion of a climate change adaptation section. All sub-sectors of tourism should have a climate change adaptation plan building on the country's strengths and addressing its' vulnerabilities. Furthermore, future studies need to look into how Government can develop and provide incentives for sustainable tourism with a specific focus in adaptation to climate change.

\section{Correspondence}

Any correspondence should be directed to Research Associate Louise Munk Klint, Centre for Tourism and Services Research, PO Box 14428, Melbourne, Victoria, Australia 8001 (louise.klint@live.vu.edu.au). 


\section{References}

Asian Development Bank (ADB) (2009). Vanuatu Economic Report 2009:

Accelerating Reform (Executive Summary). Manila: Asian Development Bank. Commonwealth of Australia. (2006). Pacific 2020 - Challenges and Opportunities for Growth. Canberra: AusAid.

Becken, S., \& Hay, J. E. (2007). Tourism and Climate Change: Risks and Opportunities. Clevedon: Channel View Publications.

Constitution of the Republic of Vanuatu - Consolidated Edition 2006 (1980).

Council of Australian Governments (COAG). (2007). National Climate Change Adaptation Framework. Barton: COAG Unit.

Dazé , A., Ambrose, K., \& Ehrhardt, C. (2009). Climate Vulnerability and Capacity Analysis Handbook (1st ed.). Chatelaine: CARE International.

DeLacy, T. \& Lipman, G. (2010). GreenEarth.travel: Moving to Carbon Clean Destinations. In: Scott, C. (ed.) (2010). Tourism and the Implications of Climate

Change: Issues and Actions.Bingley, UK: Emerald Group Publishing.

Dredge, D., \& Jenkins, J. (2007). Tourism Planning and Policy. Milton: John Wiley \& Sons Australia Ltd.

Garnaut, R. (2008). The Garnaut Climate Change Review. Port Melbourne: Cambridge University Press.

Green, D. (2008). From Poverty to Power: How Active Citizens and Effective States can Change the World. Oxford: Oxfam International.

Gunn, C. A. (1994). Tourism Planning: Basics, Concepts, Cases (3rd ed.). Washington, DC: Taylor \& Francis.

Gössling, S. H., C. Michael (Ed.). (2006). Tourism and Global Environmental Change: Ecological, Social, Economic and Political Interrelationships. Milton Park: Routledge.

Hall, C. M., \& Higham, J. (Eds.). (2005). Tourism, Recreation and Climate Change. Clevedon: Channel View Publications.

Hall, C. M., \& Jenkins, J. M. (1995). Tourism and Public Policy. London: Routledge. Harrison, D., (2003). Pacific Island Tourism. Cammeray: Cognizant Communication Corporation.

Intergovernmental Panel on Climate Change. (2007a). Climate Change 2007: The Physical Science Basis. Contribution of Working Group I to the Fourth 
Assessment Report of the Intergovernmental Panel on Climate Change. New York.

Intergovernmental Panel on Climate Change. (2007b). Climate Change 2007:

Impacts, Adaptation and Vulnerability. Contribution of Working Group II to the Fourth Assessment Report of the Intergovernmental Panel on Climate Change. New York.

Jiang, M., DeLacy, T., \& Noakes, S. (2009). Tourism, the Millenium Development Goals and Climate Change in the South Pacific Islands. Paper presented at the Millenium Development Goals (MDG) Conference.

Jiang, M., Dominey-Howes, D., Wong, E., Harrison, D., Go, S. T., Horoi, R., Noakes, S. \& Delacy, T. (2009) PT-CAP Technical Report No. 1: PT-CAP Engagement and Context. Footscray, Centre for Tourism and Services Research.

Jopp, R., DeLacy, T., \& Mair, J. (2010). Developing a Framework for Regional Destination Adaptation to Climate Change. Current Issues in Tourism, iFirst article.

Leiper, N. (2004) Tourism Management, Frenchs Forest, Pearson Education Australia.

Lincoln, Y. S., \& Guba, E. G. (1985) Naturalistic Inquiry. Beverly Hills, CA: Sage Publications, Inc.

Maclellan, N., Keough, L., Richards, J.-A., Pride, J., Ensor, J., Dent, K., et al. (2009). The Future is Here: Climate Change in the Pacific. Carlton: Oxfam.

McIntosh, R. W., Goeldner, C. R., \& Ritchie, J. R. B. (1995). Tourism - Principles, Practices, Philosophies (7 ed.). New York: John Wiley \& Sons Inc.

Méheux, K., \& Parker, E. (2004). Tourist Sector Preceptions of Natural Hazards in Vanuatu and the Implications for a Small Island Developing State. Tourism Management, 27(2006), 69-85.

Minichiello, V., Aroni, R., Timewell, E., \& Alexander, L. (1995). In-depth Interviewing: Principles, Techniques, Analysis (2 ed.). Melbourne: Longman Australia Pty Ltd.

Nadkarni, D. (2007). Vanuatu: Tourism Booms but Could Do Better. Retrieved from http://www.islandsbusiness.com/islands_business/index_dynamic/containerNa $\underline{\text { meToReplace }=\text { MiddleMiddle/focusModuleID=18186/overideSkinName=issu }}$ eArticle-full.tpl

Parliament of Vanuatu. (2009). Parliament of Vanautu. Retrieved 22 March, 2010, 
from http://www.parliament.gov.vu/index.html

Patton, M. Q. (2002). Qualitative Research \& Evaluation Methods (3rd ed.).

Thousand Oaks: Sage Publications, Inc.

Pearman, G. (2008). Climate Change: Risk in Australia under Alternative Emissions Futures Parkes: Department of Treasury.

Preston, B. L., Suppiah, R., Macadam, I., \& Bathols, J. (2006). Climate Change in the Asia/Pacific Region - A Consultancy Report prepared for the Climate Change and Development Roundtable. Clayton: Commonwealth Scientific and Industrial Research Organisation (CSIRO).

Republic of Vanuatu, Global Environment Facility, United Nations Development Program, United Nations Framework Convention on Climate Change, \& National Advisory Committe on Climate Change. (2007). National Adaptation Programme for Action (NAPA). Port Vila: Republic of Vanuatu.

Riegl, B., Bruckner, A., Coles, S. L., Renaud, P., \& Dodge, R. E. (2009). Coral Reefs - Threats and Conservation in an Era of Global Change. In R. S. Ostfeld \& W. H. Schlesinger (Eds.), The Year in Ecology and Conservation Biology (Vol. 2009, pp. 136-186). New York: New York Academy of Sciences.

Sanderson, J., \& Islam, S. M. N. (2007). Climate Change and Economic Development: SEA Regional Modelling and Analysis. New York: Palgrave Macmillan.

Scheyvens, R., \& Momsen, J. (2008). Tourism in Small Island States: From Vulnerability to Strengths. Journal of Sustainable Tourism, 16(5), 491-510.

Scott, D., Amelung, B., Becken, S., Ceron, J.-P., Dubois, G., Gössling, S., et al. (2008a). Climate Change and Tourism - Responding to Global Challenges. Madrid and Paris.

Scott, D., de Freitas, C., \& Matzarakis, A. (2008b). Adaptation in the Tourism and Recreation Sector. In K. L. Ebi \& I. Burton (Eds.), Biometerology for Adaptation to Climate Variability and Change. Dordrecht: Kluwer Academic Publishing.

Sem, G., \& Moore, R. (2009). The Impact of Climate Change on the Development Prospects of the Least Developed Countries and Small Island Developing States. New York: United Nations Office of the High Representative for the Least Developed Countries, Landlocked Developing Countries and Small Island Developing States. 
Silas-Nimoho, L. \& Whyte, J. (1999) Vanuatu National Communication to the Conference of the Parties to the United Nations Framework Convention on Climate Change. Port Vila, Meterological Services.

Simpson, M.C., Gössling, S., Scott, D., Hall, C.M. and Gladin, E., (2008): Climate Change Adaptation and Mitigation in the Tourism Sector: Frameworks, Tools and Practices. UNEP, University of Oxford, UNWTO, WMO: Paris, France.

Stern, N. (2006). The Economics of Climate Change: The Stern Review. Cambridge: Cambridge University Press

The World Bank. (2010). World Development Report 2010: Development and Climate Change. Washington: The International Bank for Reconstruction and Development / The World Bank.

United Nations Economic and Social Commission for Asia and the Pacific (UNESCAP) (2009). Statistical Yearbook for Asia and the Pacific 2008. Bangkok: UNESCAP Statistics Division.

United Nations Office of the High Representative for the Least Developed Countries Landlocked Developing Countries and Small Island Developing States (UNOHRLLS). (2010). List of Small Island Developing States Retrieved 5 January, 2010, from http://www.un.org/special-rep/ohrlls/sid/list.htm Vanuatu National Statistics Office (VNSO). (2007). 2004 Visitor Survey Report. Port Vila: Vanuatu National Statistics Office.

Vanuatu National Statistics Office (VNSO). (2009). Tourism Statistics. Retrieved 12 September, 2009, from http://www.spc.int/prism/Country/VU/stats/TOURISM/tourism-index.htm Vanuatu Tourism Office. (2009). Vanuatu Islands. Retrieved 28 August, 2009, from http://vanuatu.travel/

Weaver, D., \& Oppermann, M. (2000). Tourism Management. Milton: John Wiley \& Sons Australia Ltd.

Wong, E.P.Y., Mistilis, N., Dwyer, L. (2010). A Framework for Analyzing Intergovernmental Collaboration - The case of ASEAN Tourism. Tourism Management. In press. Available online 8 April 2010. 